\title{
Role of Founder Cell Deficit and Delayed Neuronogenesis in Microencephaly of the Trisomy 16 Mouse
}

\author{
Tarik F. Haydar, ${ }^{1}$ Richard S. Nowakowski, ${ }^{3}$ Paul J. Yarowsky, ${ }^{2}$ and Bruce K. Krueger ${ }^{1}$ \\ Departments of ${ }^{1}$ Physiology and ${ }^{2}$ Pharmacology and Experimental Therapeutics, University of Maryland School of \\ Medicine, Baltimore, Maryland 21201, and '3Department of Neuroscience and Cell Biology, University of Medicine and \\ Dentistry of New Jersey-Robert Wood Johnson Medical School, Piscataway, New Jersey 08854
}

Development of the neocortex of the trisomy 16 (Ts16) mouse, an animal model of Down syndrome (DS), is characterized by a transient delay in the radial expansion of the cortical wall and a persistent reduction in cortical volume. Here we show that at each cell cycle during neuronogenesis, a smaller proportion of Ts16 progenitors exit the cell cycle than do control, euploid progenitors. In addition, the cell cycle duration was found to be longer in Ts16 than in euploid progenitors, the Ts16 growth fraction was reduced, and an increase in apoptosis was observed in both proliferative and postmitotic zones of the developing Ts16 neocortical wall. Incorporation of these changes into a model of neuronogenesis indicates that they are sufficient to account for the observed delay in radial expansion. In addition, the number of neocortical founder cells, i.e., precursors

The growth of the mammalian cerebral cortex begins during mid-gestation as the proliferating progenitor cells lining the ventricle in the pseudostratified ventricular epithelium (PVE) begin to produce neurons, which then migrate radially toward the pial surface to populate the cortical plate (CP) (Rakic, 1972). The final number of neurons in the mature cortex is determined by the number of neocortical founder cells present at the beginning of neuronogenesis (Rakic, 1995; Haydar et al., 1999), by the proliferation of the PVE progenitor population during neuronogenesis (Caviness et al., 1995; Kornack and Rakic, 1998), and by cell death (Oppenheim, 1991; Ferrer et al., 1992; Blaschke et al., 1996; Kuida et al., 1996, 1998; Haydar et al., 1999). Although a secondary proliferative population in the subventricular zone (SVZ), which lies superficial to the PVE, may also generate neurons that populate the $\mathrm{CP}$, experimental evidence in mice suggests that the SVZ contributes at most 5\% of CP neurons (Takahashi et al., 1995b). The contributions of founder cell number and the proliferation of neuroblasts to final cortical size can be seen in the enormous phylogenetic differences in the numbers of neurons between large and small mammalian cortices. For example, neuronogenesis of the mouse neocortex proceeds over 11 cell cycles yielding about 140 postmitotic neurons per founder cell (Taka-

Received July 8, 1999; revised March 2, 2000; accepted March 9, 2000.

This work was supported by National Institutes of Health Grants AG10686 (B.K.K.), HD01046 (P.J.Y.), NS33443 (R.S.N.), and T32NS07375 (T.F.H.), National Aeronautics and Space Administration NAG2-950 (R.S.N.), and Zeneca Pharmaceuticals (B.K.K.).

Correspondence should be addressed to Dr. Bruce K. Krueger, Department of Physiology, University of Maryland School of Medicine, 655 W. Baltimore Street, Baltimore, MD, 21201. E-mail: bkrueger@umaryland.edu.

Dr. Haydar's present address: Section of Neurobiology, Sterling Hall of Medicine, Yale University School of Medicine, 333 Cedar Street, New Haven, CT 06510.

Copyright $\odot 2000$ Society for Neuroscience $0270-6474 / 00 / 204156-09 \$ 15.00 / 0$ present just before neuronogenesis begins, is reduced by $26 \%$ in Ts16 mice, leading to a reduction in overall cortical size at the end of Ts16 neuronogenesis. Thus, altered proliferative characteristics during Ts16 neuronogenesis result in a delay in the generation of neocortical neurons, whereas the founder cell deficit leads to a proportional reduction in the overall number of neurons. Such prenatal perturbations in either the timing of neuron generation or the final number of neurons produced may lead to significant neocortical abnormalities such as those found in DS.

Key words: development; neocortex; trisomy 16; neuronogenesis; Down syndrome; proliferation; programmed cell death; apoptosis

hashi et al., 1996a). In contrast, it has been estimated that primate neuronogenesis begins with four to five times as many founder cells and lasts approximately 28 cell cycles, producing up to 400 times as many neurons per founder (Caviness et al., 1995; Rakic, 1995). Despite an overall brain size that is larger by several orders of magnitude, the thickness of the primate cortex is only about twice that of the mouse, indicating that the radial thickness of a functional unit of cortex is largely conserved, independently of overall brain size. Importantly, disorders of brain development involving abnormalities of the neuroprogenitor population may lead to microencephaly and cognitive dysfunction. In particular, Down syndrome (DS; trisomy 21), the leading genetic cause of mental retardation, which is characterized by a reduced number of cortical neurons and abnormal synaptic connections (Crome and Stern, 1972; Ross et al., 1984; Wisniewski et al., 1986), may result from abnormalities in founder cell number or altered neuroblast proliferation during neuronogenesis.

Because the opportunities for studying the pathogenesis of prenatal cortical abnormalities in DS are limited, we have instead characterized the cellular parameters that contribute to neuronogenesis in the developing neocortex of the trisomy 16 (Ts16) mouse, an animal model for DS. Because the distal portion of mouse chromosome 16 is syntenic with most of the distal portion of human chromosome 21 (Reeves et al., 1986; Holtzman and Epstein, 1992), mouse Ts16 and DS share a common genetic defect. Previously, we described morphogenetic abnormalities during embryonic development of the Ts16 neocortex (Haydar et al., 1996), including reductions in cortical size and a delay in radial growth of the intermediate zone (IZ) and CP, and established that the delay in radial growth is largely overcome by the end of neuronogenesis. 
The goal of this study was to determine the relative contributions of the initial size, proliferation, and survival of the founder cell population to the abnormalities observed during development of the Ts16 neocortex. We found that Ts16 neocortical neuronogenesis begins with a smaller founder cell population leading to a proportionately smaller cortex at the end of the neuronogenetic period. Alterations in the properties of the proliferating progenitors in the Ts16 PVE cause a delay in reaching normal radial thickness, resulting in a shortage of postmitotic $\mathrm{CP}$ neurons at the beginning and middle of the neuronogenetic period. These findings detail the complex series of developmental events that result in a particular set of abnormalities in the Ts16 mouse neocortex and raise the possibility that a similar series of events during human prenatal neuronogenesis may lead to the neocortical defects underlying mental retardation in DS.

\section{MATERIALS AND METHODS}

Animal breeding and karyotyping. Ts16 embryos and control euploid littermates were generated as previously described (Gropp et al., 1975; Haydar et al., 1996). Briefly, males doubly heterozygous for the Robertsonian chromosome translocation $\mathrm{Rb}(6,16) 24 \mathrm{LuB} \times \mathrm{Rb}(16,17) 7$ BNRF1 were mated with C57BL/6J female mice (Jackson Laboratory, Bar Harbor, ME). Littermates are genetically identical except for the triplication of chromosome 16 in the trisomic fetuses. Couples were paired at 5 P.M. and separated at 9 A.M. the following morning. The day of separation was designated gestational day E1. Fetal brains were immersed in $4 \%$ paraformaldehyde/PBS fixative overnight at $4{ }^{\circ} \mathrm{C}$. Corresponding fetal livers were used for karyotype analysis of metaphase chromosome spreads to determine the genotype of each fetus E14 and younger. For E15 and older fetuses, we have established that Ts16 individuals can be identified with $100 \%$ accuracy by physical characteristics alone, based on metaphase chromosome analysis in more than 350 cases (Bambrick et al., 1996; Haydar et al., 1996).

Tissue sectioning and histology. For Nissl staining and BrdU immunohistochemistry, fetal brains were dehydrated through a series of ascending ethanol concentrations and then left overnight in $100 \%$ butanol. The heads were cleared in xylene for $1 \mathrm{hr}$, then infiltrated for $1.5 \mathrm{hr}$ with paraffin at $60^{\circ} \mathrm{C}$ under vacuum before being imbedded in paraffin. Coronal sections $(5 \mu \mathrm{m})$ from Ts16 and euploid littermate brains were collected on Superfrost Plus slides (Fisher Scientific, Springfield, NJ) and air-dried. Sections were deparaffinized with xylene and then rehydrated through a series of descending ethanol concentrations and washed in 0.1 M Tris. Sections were then stained with the appropriate antibody or processed for autoradiography (see below). For propidium iodide staining and terminal deoxynucleotidyl transferase-mediated biotinylated dUTP nick end labeling (TUNEL), fixed heads were cryoprotected in $30 \%$ sucrose, and $25 \mu \mathrm{m}$ sections were cut on a cryostat and applied to gelatin-subbed slides.

Cell counting. Although some experiments presented here required stereological counting methods (e.g., see "Founder cell measurements" below), most of the present analyses are based on relative differences in counts of nuclei in histological brain sections from control euploid and Ts16 neocortex; such counts are valid only if they are "unbiased" (Coggeshall and Lekan, 1996). We have therefore addressed this issue by measuring the area of nuclear profiles in confocal microscope sections from euploid and Ts16 cortices to determine whether the size of Ts16 nuclei is normal. Optical sections of $0.5 \mu \mathrm{m}$ thickness were obtained from propidium iodide-stained $25 \mu \mathrm{m}$ frozen brain sections on a Zeiss LSM410 (Carl Zeiss, Thornwood, NY) laser-scanning microscope. An image processing program (Metamorph, Universal Imaging, West Chester, PA) was used to determine an area distribution histogram of nuclear profiles. The areas of $\sim 3000$ nuclei per animal were then measured each day from E14 to E18. Our results indicate that the nuclear size distributions and cellular packing densities in Ts16 and euploid neocortices are indistinguishable [Haydar et al. (1996); and data not shown], eliminating the need to use stereological methods (Sterio, 1984; Coggeshall and Lekan, 1996) for determining relative differences in nuclear counts.

Cell nuclei were counted in the future somatosensory cortex [for example see Haydar et al. (1996)] in alternating 5- $\mu$ m-thick coronal paraffin sections using a Leitz Ortholux microscope equipped with a square reticle divided into 100 boxes $(10 \times 10 \mu \mathrm{m})$. Counts were made at a consistent position on the dorsal pallium at the medial border of the lateral ventricle. The grid of the reticle was positioned such that the first row (bin 1) of 10 boxes contained the cells at the ventricular surface. The cells contained within each successive bin were counted beginning at the ventricular surface (bin 1). A cell was considered to reside within a bin if its nucleus was located on the medial or dorsal border of the bin but not if it touched the lateral or ventral border. The reticle was repositioned to accommodate neocortical walls of $>100 \mu \mathrm{m}$ thickness. The euploid neocortex typically spans 16 bins at E14 and 42 bins at E16, whereas the Ts16 neocortex spans 13 and 34 bins at these embryonic ages (Haydar et al., 1996). As in previous reports, cells were counted as PVE cells if they were contained within bins 1-7 (Takahashi et al., 1993, 1995a). Six to eight alternating sections from each brain were counted in this manner, and the data were analyzed by paired $t$ test to determine any significant differences between Ts16 and euploid cell counts.

Founder cell measurements. The number of PVE cells present before neuronogenesis begins was estimated in $10 \mu \mathrm{m}$ serial forebrain sections of paraffin-embedded, Nissl-stained E10 euploid and Ts16 embryos using stereological methods ( $n=4$ embryos per genotype). The cell density in the PVE was determined using a stereological counting frame (Williams and Rakic, 1988) and was found to be uniform throughout the PVE and to be the same in euploid and Ts16 brains. On each section, the PVE area was then measured using NIH Image software and multiplied by the thickness and cell density. Finally, the measurements from all sections of the neocortical epithelium were combined, yielding the number of founder cells.

Cortical volume index. To compare actual morphological findings with the model predictions (see below), an estimate (volume index) of the volume of the postmitotic regions of the cortex was calculated as follows: the average of the thickness of the IZ $+\mathrm{CP}$ in coronal sections at the levels of the future sensorimotor cortex and the fornix rostral to the anterior commissure (measured midway between the medial and lateral angles of the lateral ventricles) was computed for Ts16 and euploid cortices at various embryonic ages throughout neuronogenesis using data in Haydar et al. (1996) $(n=5$ per genotype). This average thickness was multiplied by the product of the rostral-caudal and lateral-medial dimensions of the gross cortex for each age (Haydar et al., 1996) to estimate a "cortical volume index" for E13, E14, E16, and E18. This index, although not a true volume measurement, can be used to identify relative volume changes in the Ts16 cortex. Importantly, because the cellular density in the developing Ts 16 neocortical wall is equal to that of controls (Haydar et al., 1996), these measurements can be used to compare the number of Ts16 neurons with that of controls. For the purpose of comparing neocortical growth predicted by the neuronogenetic model with actual brain size (see Fig. 7), the volume indices of the euploid and Ts16 IZ + CP at various embryonic ages were normalized to the euploid volume index at E18, which was set to $100 \%$.

Duration of $S$-phase $\left(\mathrm{T}_{\mathrm{S}}\right)$. S-phase duration was determined by a double-labeling paradigm in which an injection of 5-bromo-2'deoxyuridine (BrdU, $50 \mu \mathrm{g} / \mathrm{gm}$ body weight, i.p.) was followed $2 \mathrm{hr}$ later with an injection of $\left[{ }^{3} \mathrm{H}\right]$ thymidine $\left({ }^{3} \mathrm{H}-\mathrm{dT}, 5 \mu \mathrm{Ci} / \mathrm{gm}\right.$ body weight, i.p.). Thirty minutes later, the mother was killed and the fetuses were processed ( $n=6$, each group); BrdU-and ${ }^{3} \mathrm{H}$-dT-labeled nuclei were identified by immunohistochemistry and autoradiography (see below). Under these conditions, the labeling efficiencies and detectability of the two tracers were approximately equivalent, and there was no evidence of significant tracer interactions that depend on the order of administration (Hayes and Nowakowski, 2000). $T_{\mathrm{S}}$ was calculated as:

$$
T_{\mathrm{S}}=2 \mathrm{hrs} \times B / A,
$$

where $B$ is the number of all $\mathrm{BrdU}^{+}$cells per section and $A$ is the number of $\mathrm{BrdU}^{+}$cells per section that were not ${ }^{3} \mathrm{H}$-dT-labeled. At the concentration used in this study, BrdU is not cytotoxic and does not cause progenitor anomalies (Biggers et al., 1987; Nowakowski et al., 1989; Takahashi et al., 1992). The availability of BrdU during this and the other experiments detailed below is determined by the rate of clearance by the maternal liver (Kriss and Revesz, 1962) and therefore is the same for littermate Ts16 and euploid fetuses.

Duration of cell cycle $\left(\mathrm{T}_{\mathrm{C}}\right)$ and growth fraction. The duration of the rest of the cell cycle $\left(T_{\mathrm{C}}-T_{\mathrm{S}}\right)$ is the time required to label $100 \%$ of the proliferating cells in the PVE by cumulative BrdU injections (Takahashi et al., 1995a). The fraction of PVE cells that are proliferating [growth fraction $(G F)$ ] is the maximal fraction of cells labeled by BrdU reached at $T_{\mathrm{C}}-T_{\mathrm{S}}$. BrdU was injected every $2 \mathrm{hr}(50 \mu \mathrm{g} / \mathrm{gm}$ body weight, i.p. $)$ 
with survival times of $30 \mathrm{~min}$ and $8,11,12$, and $14 \mathrm{hr}(n=3-8$ for each time point per genotype) as described previously (Nowakowski et al., 1989; Takahashi et al., 1995a). The labeling index (LI), or fraction of PVE cells labeled by BrdU, was determined at each time by BrdU immunohistochemistry. All cumulative labeling experiments were started at 5:30 A.M. on E14.

Immunocytochemistry. Progenitors that had incorporated BrdU into their DNA were visualized by immunohistochemical staining using antiBrdU antibody (Becton Dickenson, Cockeysville, MD). Sections were denatured with $2 \mathrm{~N} \mathrm{HCl}$ for $30 \mathrm{~min}$ and then incubated with anti-BrdU antibody (1:100 dilution) for $30 \mathrm{~min}$ in PBS at room temperature. Biotinylated secondary antibody (Vectastain ABC, Elite Mouse IgG; Vector Laboratories, Burlingame, CA) at 1:200 dilution was added for 45 min. The $A B C$ reagent was then added as per the manufacturer's instructions, and the DAB reaction was performed with $0.035 \%$ DAB in Tris, $\mathrm{pH} 7.4$, and $0.01 \% \mathrm{H}_{2} \mathrm{O}_{2}$.

${ }^{3} \mathrm{H}$-dT autoradiography. In $\mathrm{BrdU} /{ }^{3} \mathrm{H}$-dT double-label experiments, the BrdU staining always preceded autoradiography. Slides with sections from animals injected with ${ }^{3} \mathrm{H}-\mathrm{dT}$ ( $n=6$ per genotype) were dried at $60^{\circ} \mathrm{C}$ overnight, dipped in NTB2 emulsion (Kodak, Rochester, NY) at $40^{\circ} \mathrm{C}$, and then dried vertically in a humidified chamber overnight. Dried slides were placed in a light-tight box at $4^{\circ} \mathrm{C}$ for $4-5$ weeks and then developed with $50 \%$ D-19 developer (Kodak) at $16^{\circ} \mathrm{C}$ for 2 min. Slides were fixed with Ektaflo (1:7, Kodak) for $5 \mathrm{~min}$, rinsed in water for $10 \mathrm{~min}$, dried, and then coverslipped in Permount (Sigma, St. Louis, MO).

Measurement of programmed cell death (apoptosis) by TUNEL. For cell death studies, $25 \mu \mathrm{m}$ frozen coronal sections from $4 \%$ paraformaldehyde-fixed brains were stained by TUNEL $(n=4$ embryos per genotype per day) (Gavrieli et al., 1992; Krueger et al., 1995). Sections from E14-E18 were treated with $0.26 \mathrm{U} / \mu 1$ transferase and $1 \times$ supplied buffer (Life Technologies, Gaithersburg, MD), and $20 \mu \mathrm{M}$ biotinylated16-dUTP (Boehringer Mannheim, Indianapolis, IN) for $60 \mathrm{~min}$ at $37^{\circ} \mathrm{C}$. Sections were then washed three times in PBS and blocked for $30 \mathrm{~min}$ with $2 \%$ BSA in PBS. The sections were then incubated with TRITCcoupled streptavidin (Jackson Immunoresearch, West Grove, PA) 1:100 in PBS for $30 \mathrm{~min}$, rinsed, and then counterstained with the nuclear stain, bis-benzimide $(1 \mu \mathrm{g} / \mathrm{ml}$, Sigma). Slides were then mounted in Citifluor (London, UK). Separate controls with DNase-treated sections or sections lacking transferase in the reaction mixture were used to determine the specificity of the method. The number of $\mathrm{TUNEL}^{+}$nuclei per cortical wall was determined at the level of the future somatosensory cortex using confocal microscopy. Rates of apoptosis (cells per day) were determined as the fraction of total bis-benzimide-stained nuclei that were TUNEL ${ }^{+}$, multiplied by $24 \mathrm{hr}$, and divided by the published clearance rate of $2.5 \mathrm{hr}$ [for apoptotic cells in neonatal mouse subventricular zone; Thomaidou et al. (1997)]. The rate of apoptosis for the proliferative $\left(D_{\mathrm{P}}\right)$ and postmitotic $\left(D_{\mathrm{O}}\right)$ neocortical regions was determined separately by determining the proportion of $\mathrm{TUNEL}^{+}$cells within the VZ and IZ + CP. We believe that TUNEL is a more accurate measure of apoptosis than counting pyknotic nuclei because embryonic erythrocytes often appear pyknotic and the TUNEL method identifies dying cells with both nonpyknotic and pyknotic nuclei (Coggeshall et al., 1993; Krueger et al., 1995).

Postmitotic (Q) and proliferative (P) fractions. $Q$ for each day from E13 to the end of neuronogenesis was estimated from:

$$
\left(C P_{\mathrm{n}+1}+I Z_{\mathrm{n}+1}\right)-\left(C P_{\mathrm{n}}+I Z_{\mathrm{n}}\right)=Q_{\mathrm{n}}\left(2 * V Z_{\mathrm{n}}\right),
$$

where $n=$ the first cell cycle, $n+1=$ the next cell cycle, and $C P, I Z$, and $V Z$ represent the number of cells in the cortical plate, intermediate zone, and ventricular zone, respectively. The left side of Equation 2 describes the increase in postmitotic cells appearing within the IZ and CP from one cell cycle to the next. The right side of this equation describes how the product of a full mitotic cycle $(2 * V Z)$, multiplied by the fraction of cells $(Q)$ that does not return to the cell cycle, provides these cells. The SVZ, defined as the cells between the superficial limit of the VZ and the most superficial abventricular mitotic figure, was omitted from this measurement. A third order regression fit to $Q$ versus time was used to obtain $P$ and $Q$ for each cell division during neuronogenesis. $P$ was calculated as $1-Q$. Our estimates of euploid $Q$ and $P$ are similar to the values obtained previously in CD1 mice using other methods (Takahashi et al., 1996a). Thus, there do not appear to be significant differences in these parameters between mouse strains. The duration of the Ts16 neuronogenetic interval was determined to be equal to that of controls, because in both genotypes the first postmitotic cells of the preplate are born on E11 (A. Cheng, P. J. Yarowsky, and B. K. Krueger, unpublished obser- vations), and no paraventricular mitotic figures are apparent after E17 [Haydar et al. (1996); data not shown]. Cortical neuronogenesis therefore occurs between E11 and E17 in both Ts16 and euploid brains. Thus, as has been previously reported for normal mouse neocortex (Takahashi et al., 1996), $Q$ starts at 0 on E11 and reaches 1 on E17 in Ts16.

Mathematical modeling. The measured proliferative parameters of the Ts16 and control, euploid PVE were incorporated into a neuronogenetic model of mouse cortical development (modified from Takahashi et al., 1996), and the model predictions were compared with the observed phenotype (Haydar et al., 1996). Unless otherwise stated, all calculations start with one "average" founder cell for both the euploid and Ts16 models (Caviness et al., 1995). The predicted volume of the PVE at each cell cycle $(n)$ was determined from Equation 3.

$$
P V E_{\mathrm{n}}=P_{1} * \prod_{\mathrm{n}=2}^{\mathrm{N}} 2 * P_{\mathrm{n}} *\left(1-D_{\mathrm{P}}\right)_{\mathrm{n}}
$$

where $P_{\mathrm{n}}$ is the value of $P$ for cell cycle $n$, and $D_{\mathrm{P}}$ is the fraction of $\mathrm{TUNEL}^{+}$cells per cell cycle within the cortical proliferative zone. $N$ is the total number of cell cycles during neuronogenesis and is equal to 10 for Ts16 and 11 for controls (see below). The predicted cumulative output of neocortical neurons from the PVE was then determined from Equation 4.

$$
O U T_{\text {cum }}=Q_{1}+\sum_{\mathrm{n}=2}^{\mathrm{N}} 2 * Q_{\mathrm{n}} * P V E_{\mathrm{n}-1} *\left(1-D_{\mathrm{Q}}\right)_{\mathrm{n}},
$$

where $Q_{\mathrm{n}}$ is the value of $Q$ for cell cycle $n$ and $D_{\mathrm{O}}$ is the fraction of apoptotic cells per cell cycle in the postmitotic neocortical layers. The correspondence between embryonic day (on which morphometric measurements were made) and cell cycle number (on which the model is based) was established for the euploid controls as described by Takahashi et al. (1996a). For Ts16, the calculation was repeated using measured values for $G F, Q, D_{\mathrm{P}}, D_{\mathrm{Q}}$ and $T_{\mathrm{C}}$. $T_{\mathrm{C}}$ in Ts 16 was assumed to increase by $1 \mathrm{hr}$ for each cell cycle because of the measured increase in Ts16 S-phase duration (see Results). Because the Ts16 neuronogenetic period ends at the same time as controls, it appears that only 10 cell cycles are completed in Ts16 rather than the normal 11 because of the longer Ts16 cell cycle. Accordingly, in our analysis of Ts16 cortical neuronogenesis using a modification of the mathematical model described by Takahashi et al. (1996) (see below), we used 11 cell cycles for the duration of the euploid neuronogenetic period and 10 cell cycles for the Ts16 duration. Calculations of final PVE output were also made incorporating each Ts16 parameter individually (see Table 1).

\section{RESULTS}

\section{The number of telencephalic founder cells is reduced in Ts16}

The number of founder cells present in the PVE at the onset of neuronogenesis was estimated by counting the total number of cells in serial sections of the telencephalic VZ at E10 using stereological methods (Fig. 1A) (see Materials and Methods). The total number of cells in the Ts16 VZ at E10 was reduced by $\sim 26 \%$ as compared with the euploid VZ (Fig. $1 B$ ). Thus, Ts 16 neuronogenesis begins with a $26 \%$ deficit in founder cells.

\section{S-phase is longer in Ts16 PVE progenitors}

To estimate $T_{\mathrm{S}}$, BrdU was injected into the mother at E14 to label a cohort of S-phase cells. An injection of ${ }^{3} \mathrm{H}-\mathrm{dT} 2 \mathrm{hr}$ later labeled a second cohort, partially overlapping the first (Fig. $2 A$ ). Therefore, during the $2 \mathrm{hr}$ interval between injections, some of the progenitors of the first cohort exited S-phase and were not double-labeled by the ${ }^{3} \mathrm{H}-\mathrm{dT}$ pulse (i.e., this cohort was labeled by BrdU but not ${ }^{3} \mathrm{H}-\mathrm{dT}$ ). In contrast, the $\mathrm{BrdU}^{+}$cells remaining in S-phase at the time of the ${ }^{3} \mathrm{H}$-dT injection were double-labeled. $T_{\mathrm{S}}$ was calculated using Equation 1 as explained in Materials and Methods. Because approximately one-half of the BrdU-labeled cells had left S-phase $2 \mathrm{hr}$ after the BrdU injection and thus were 

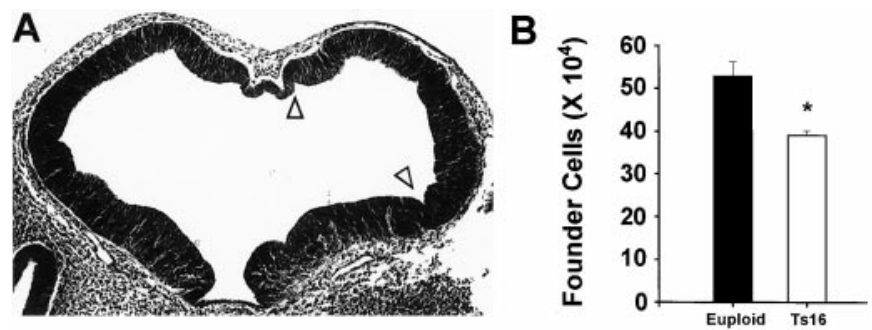

Figure 1. Founder cell population is reduced in Ts16. $A$, Serial coronal sections of E10 brain were Nissl-stained. $B$, The number of cells in the telencephalic ventricular epithelium for each section, measured between the arrowheads in $A$, was determined by stereological methods. The total number of cells was determined by summing over all sections. The mean total number of VZ cells for three Ts16/euploid pairs is significantly different $\left({ }^{*} p<0.05\right)$.

not labeled with ${ }^{3} \mathrm{H}$-dT, the duration of S-phase $\left(T_{\mathrm{S}}\right)$ in euploid mice is $\sim 4 \mathrm{hr}$ (Fig. 2C). These results for euploid neuroblasts agree with the earlier estimates of $T_{\mathrm{S}}=3.8 \mathrm{hr}$ in mouse PVE (Takahashi et al., 1993, 1995a). In contrast, only $40 \%$ of BrdUlabeled Ts16 progenitors had exited S-phase by the time of the ${ }^{3} \mathrm{H}$-dT pulse leading to an estimate of $T_{\mathrm{S}}=4.9 \mathrm{hr}$ in the Ts16 PVE (Fig. $2 C$ ), a significant increase of $23 \%$ over controls $(p<$ $0.05)$.

\section{$T_{\mathrm{C}}-T_{\mathrm{S}}$ is normal during Ts16 neuronogenesis}

The duration of the three remaining phases of the cell cycle (G2 $+\mathrm{M}+\mathrm{G} 1$ or $T_{\mathrm{C}}-T_{\mathrm{S}}$ ) is the time required for a cell that had just exited S-phase to complete the rest of the cell cycle and enter the subsequent S-phase. This duration was determined by cumulative BrdU labeling beginning at E14 as described previously (Nowakowski et al., 1989; Takahashi et al., 1995a). Using this protocol, successive cohorts of cells were labeled as they entered S-phase. Accordingly, the PVE LI rises linearly in both euploid and Ts16 cortices (Fig. 3C). Maximum LI and the time at which the LI reaches a maximum correspond to the $G F$ (the fraction of PVE cells that are proliferating) and $T_{\mathrm{C}}-T_{\mathrm{S}}$, respectively (Takahashi et al., 1995a).

These data reveal several important properties of the Ts16 PVE population at E14. First, $T_{\mathrm{C}}-T_{\mathrm{S}}$ is $11.7 \mathrm{hr}$ for both the euploid and Ts16 PVE, which means that $\mathrm{T}_{\mathrm{G} 2+\mathrm{M}+\mathrm{G} 1}$ is normal in Ts16 at E14. This value is not significantly different from the previous estimate of $T_{\mathrm{C}}-T_{\mathrm{S}}=11.3 \mathrm{hr}$ in CD1 mice (Takahashi et al., 1993). By combining these results with our measurements of $T_{\mathrm{S}}$ above, $T_{\mathrm{C}}=15.7 \mathrm{hr}$ for control brains and $T_{\mathrm{C}}=16.6 \mathrm{hr}$ in Ts16 brains. Second, the euploid $G F=93 \%$, whereas the Ts16 GF= $86 \%(p<0.001)$. Previous reports indicate that the PVE $G F \approx$ $100 \%$ throughout the entire neuronogenetic period (Takahashi et al., 1995a). The slightly lower euploid $G F$ presented here is probably caused by differences in nuclear access attributable to fixation techniques ( $70 \%$ ethanol vs $4 \%$ paraformaldehyde). Nevertheless, the Ts16 GF is reduced by $7 \%$, indicating that fewer Ts16 progenitor cells were proliferating during the $14 \mathrm{hr}$ of BrdU administration.

\section{Increased cell death in the developing Ts16 neocortex}

To evaluate the role of cell death in the abnormal development of the Ts16 neocortex, apoptosis during neuronogenesis was measured by TUNEL (Fig. 4). The incidence of cell death within the euploid pallium was low. There was an average of one apoptotic nucleus per $20-\mu \mathrm{m}$-thick section of cortical wall (Fig. $4 A$ ). The number of TUNEL ${ }^{+}$cells within the Ts16 pallium was also small,
A
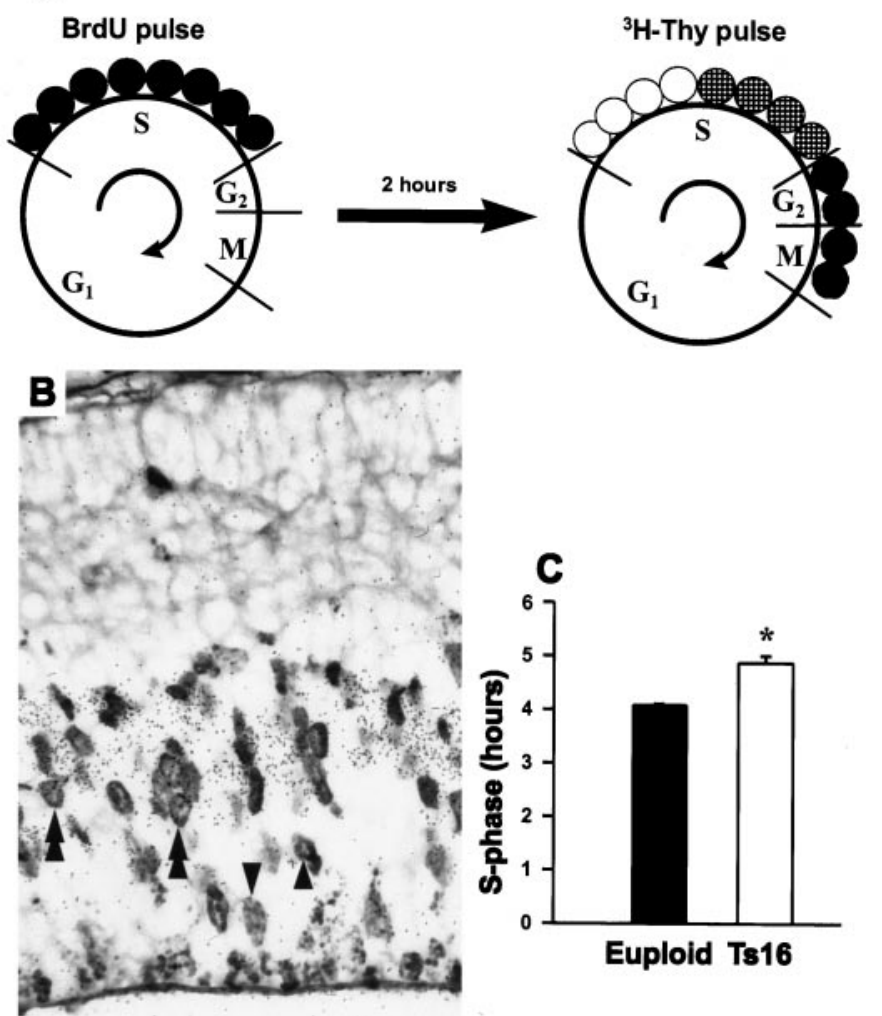

Euploid Ts16

Figure 2. Double-labeling reveals an increase in S-phase in Ts16 progenitors. $A$, A cohort of cells in S-phase was initially labeled by an injection of BrdU into the pregnant dam on E14 (filled circles). This was followed $2 \mathrm{hr}$ later by a pulse of ${ }^{3} \mathrm{H}$-dT to determine the percentage of the original, BrdU-labeled cohort that had exited S-phase during the $2 \mathrm{hr}$ interval. Cells that had not exited were identified as $B r d U^{+}-{ }^{3} \mathrm{H}-\mathrm{dT}^{+}$ (checkered circles). Cells recruited into S-phase after the initial BrdU injection remained ${ }^{3} \mathrm{H}-\mathrm{dT}^{+}$only (open circles). B, Two classes of BrdUlabeled cells resulted from the injection paradigm: BrdU-only cells that had exited S-phase before the second injection (arrowheads) and cells labeled with both BrdU and ${ }^{3} \mathrm{H}$-dT that were in S-phase for both injections (double arrowheads). $C$, The duration of S-phase $\left(T_{\mathrm{S}}\right)$ at E14 was calculated based on the number of $\mathrm{BrdU}^{+}$-only cells as a percentage of all $\mathrm{BrdU}^{+}$cells (Eq. 1). $T_{\mathrm{S}}$ is longer in the Ts16 PVE (4.9 hr, open bar) than in euploid PVE (4.0 hr, filled bar $)$. Mean $\pm \operatorname{SEM}(n=4$ pairs $) ;{ }^{*} p<0.05$.

but between E15 and E18 the incidence of cell death was up to fourfold higher than in euploid. Moreover, the distribution of TUNEL $^{+}$cells within the euploid and Ts16 pallial walls was different. In the E16 euploid pallium, most (86\%) of the prenatal apoptosis occurs within the postmitotic layers (IZ, CP). In contrast, apoptosis within the Ts16 pallium occurs in all layers, including the proliferative layers at about the same incidence (Fig. $4 B$ ). The percentage of cells dying per day was calculated by adjusting the measured percentage of cells that were TUNEL ${ }^{+}$ by the estimated clearance rate of $2.5 \mathrm{hr}$ for neonatal mouse subventricular zone (Thomaidou et al., 1997). The resulting rate of cell death throughout neuronogenesis averaged $0.14 \%$ per day in the proliferative cells of the euploid $\mathrm{VZ}\left(D_{\mathrm{P}}\right)$ and $0.35 \%$ per day in postmitotic cells of the euploid IZ $+\mathrm{CP}\left(D_{\mathrm{Q}}\right)$. The increased incidence of apoptotic cells in the Ts16 neocortex results in an increase in $D_{\mathrm{P}}$ and $D_{\mathrm{Q}}$ to an average of 0.84 and $0.81 \%$ per day. Importantly, despite the fact that the rate of apoptosis was approximately sixfold higher than normal in the Ts16 VZ and just over twofold higher than normal in the Ts16 IZ 

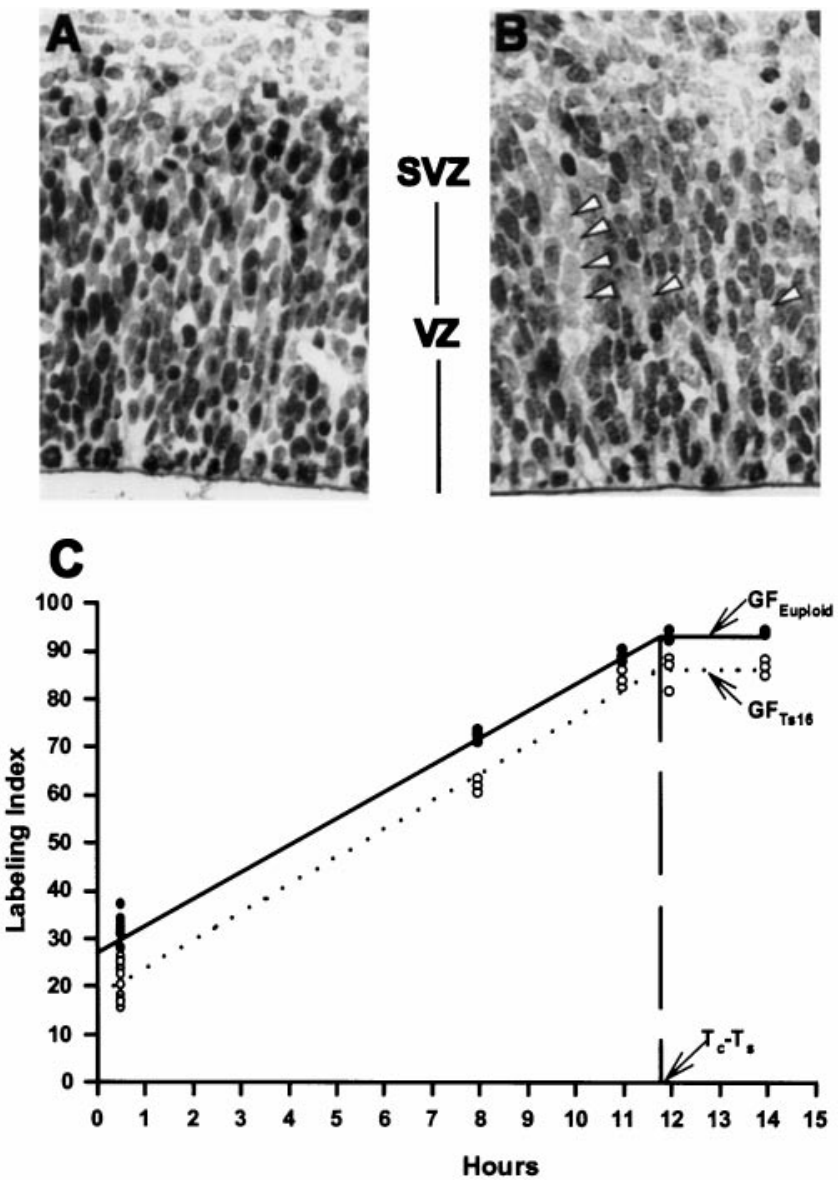

Figure 3. Figure 3. Cumulative labeling to measure $T_{\mathrm{C}}-T_{\mathrm{S}}$ and $G F$ at E14. Shown is BrdU immunoreactivity in E14 $(A)$ euploid and $(B)$ Ts16 cortical wall after BrdU had been injected every $2 \mathrm{hr}$ for $14 \mathrm{hr}$. Most euploid $\mathrm{VZ}$ cells are $\mathrm{BrdU}^{+}$, whereas there are numerous examples of ectopic, nonproliferating cells $\left(\mathrm{BrdU}^{-}\right)$remaining within this proliferative layer in the Ts16 VZ (arrowheads). C, Repetitive injections with BrdU label successively more progenitors as they enter S-phase, and the LIs for euploid (solid line) and Ts16 (dashed line) rise linearly with similar slopes. The time at which PVE labeling reached a maximum $\left(T_{\mathrm{C}}-T_{\mathrm{S}}\right)$ was 11.7 $\mathrm{hr}$ for both euploid and Ts16. The LI at $T_{\mathrm{C}}-T_{\mathrm{S}}$ represents the GF of the PVE. Ts16 GF is reduced to $86 \%$ from the euploid value of $93 \%$, indicating a decrease in the fraction of proliferating cells in the Ts16 PVE of $7 \%$. Data points are means from each fetus analyzed. LI was significantly different at each time point; $p$ values (paired $t$ test): $0.5 \mathrm{hr}, p<$ $0.0001 ; 8 \mathrm{hr}, p<0.001 ; 11 \mathrm{hr}, p<0.05 ; 14 \mathrm{hr}, p<0.01$.

$+\mathrm{CP}$, the absolute rate of cell death was too low to substantially affect cortical growth in either euploid or Ts16 pallium (see below).

\section{Model of cortical neuronogenesis modified to incorporate cell death}

As originally proposed, the neuronogenetic model for neocortical development (Takahashi et al., 1996a) implicitly assumed that cell death of the proliferating cells of the PVE was low. This is consistent with previous reports that there is little death during prenatal neocortical development (Spreafico et al., 1995; Thomaidou et al., 1997). Our finding of increased apoptosis in embryonic Ts16 neocortex, particularly in the VZ (Fig. 4), led us to modify the model by incorporating separate terms for cell death in the proliferative $\left(D_{\mathrm{P}}\right)$ and postmitotic $\left(D_{\mathrm{Q}}\right)$ populations (Eqs. 3 and 4$)$. Although the predictions arising from this modified model indicate that death plays only a small role in both normal and
Ts16 corticogenesis (Table 1), these modifications may be useful in assessing the role of proliferative death in other animal models of disease. For example, prevention of apoptosis by targeted deletion of either caspase- 3 or caspase-9, effector molecules of the apoptosis pathway, results in a hypercellular neocortex (Kuida et al., 1996, 1998), possibly attributable to death of progenitor cells before neuronogenesis (Haydar et al., 1999). The modified model presented here could be used to assess the spatiotemporal effects of these mutations on neocortical growth.

\section{The generation of neurons is delayed during Ts16 neuronogenesis}

The length of the neuronogenetic interval in Ts16 is normal because neuronogenesis begins at E11 and ends by E17 (see Materials and Methods). However, the growth and eventual size of the cortical plate is also specified by the changing proportion of PVE cells that either remain proliferative and reenter the cell cycle $(P)$ or become quiescent and exit the cell cycle $(Q)$ after each mitotic division (Takahashi et al., 1996a). Previously reported delays in growth of the cortical plate and intermediate zone (Haydar et al., 1996) suggested that the values of $P$ and $Q$ were abnormal in the Ts 16 neocortex. To estimate $P$ and $Q$, nuclei were counted in defined sectors of the dorsomedial cortical wall from the ventricular surface to the pia. The numbers of cells within the VZ, IZ, and CP were recorded and segregated into proliferative (VZ) or postmitotic (IZ and CP) groups (Fig. $5 A$ ). From these counts, $Q$ was estimated using Equation 2 as the increase in the postmitotic population as a fraction of the proliferative population after each cell cycle between E11 and E17; $P=1-Q$ (see Materials and Methods and Fig. 5 legend). $Q$ for both euploid and Ts16 cortices rises nonlinearly and reaches 1 by the end of neuronogenesis on E17 (Fig. 5B). The values of $Q$ for euploid neocortex are similar to those previously reported (Takahashi et al., 1996a). For example, $Q=0.5$ on E15 between cell cycles 7 and 8 . In contrast, $Q$ rises more slowly in the Ts16 neocortex and reaches 0.5 only between the eighth and ninth cell cycles on E16. Ts16 $P$ and $Q$ were corrected to account for the $7 \%$ reduction in $G F$ (Fig. $3 C$ ).

\section{Fewer founder cells and delayed neuronogenesis can account for the Ts16 phenotype}

Fewer founder cells, a longer cell cycle, a delayed increase in $Q$, a smaller $G F$, and increased proliferative cell death could all potentially affect the growth of the Ts16 neocortex. To determine how and when these abnormalities affect the Ts16 cortical phenotype, we incorporated these measured parameters into a model of neocortical neuronogenesis modified to incorporate cell death (see Materials and Methods). Because $T_{\mathrm{S}}$ was previously determined to be constant throughout neuronogenesis (Takahashi et al., 1995a), we assumed that the $1 \mathrm{hr}$ increase measured at E14 in Ts16 brains was constant during the entire neuronogenetic interval. We also assumed that the $G F$ was reduced by $7 \%$ (Fig. $3 B$ ) throughout neuronogenesis. Equations 3 and 4 were used to predict the growth of the euploid and Ts16 neocortex (Fig. 6). The prediction from Equation 3 (Fig. 6A) suggests that early in neuronogenesis, the Ts16 PVE remains smaller than euploid PVE. This is primarily attributable to the longer cell cycle and smaller $G F$ of the Ts16 PVE. However, because of the delayed departure of progenitors from the cell cycle (Fig. $5 B$ ), the size of the Ts16 PVE eventually exceeds that of euploid PVE (Fig. 6A).

The predicted cumulative output of postmitotic neurons (Fig. $6 B$ ) from the euploid PVE rises rapidly between E12 and E16 

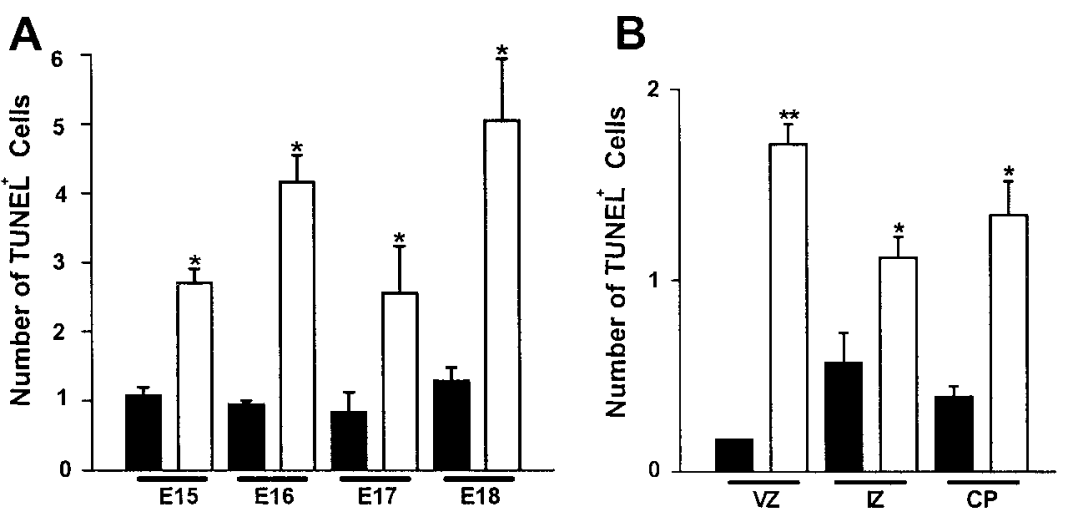

Figure 4. The incidence of apoptosis is increased in the Ts16 cortical wall. $A$, The number of apoptotic cells within the cortical wall from E15 to E18 was increased in Ts16 brains (open bars) as compared with controls (solid bars). B, Dying cells at E16 were found throughout the cortical wall in Ts16 brains, most dramatically within the proliferative ventricular zone $(V Z)$. In contrast, most apoptotic cells within euploid cortices were located in the intermediate zone $(I Z)$ and cortical plate $(C P)$, which contain postmitotic neurons. Mean $\pm \operatorname{SEM}(n=6$ pairs at each age $) ;{ }^{*} p<0.05$

and reaches a maximum at the end of neuronogenesis, as has been reported for normal, CD1 mice (Takahashi et al., 1996a). The Ts16 PVE output, however, rises more slowly between E12 and E15 largely because of the delayed increase in $Q$ causing fewer postmitotic neurons to be generated from the Ts16 PVE (Fig. 5B). However, the delayed increase in $Q$ also results in more Ts16 neuroblasts remaining in the cell cycle, leading to an enlarged Ts16 PVE after E15 (Fig. 6A). Thus, by the end of neuronogenesis at E17, a similar number of postmitotic neurons per founder cell have been generated in euploid and Ts16 cortex (Table 1, Fig. 6B). It should be noted that the agreement between the model predictions using Ts16 parameters (Fig. 6B) and the observed time course of growth of the Ts16 cortex (Haydar et al., 1996) supports the validity of the assumptions that $T_{\mathrm{S}}$ and $G F$ measured at E14 reflect the values of these parameters throughout Ts16 neuronogenesis (see above).

We then incorporated the decrease in Ts16 founder cells into the calculations to compare the cumulative output predicted by the model to the cortical volume index determined for the actual Ts16 and euploid neocortex. We previously showed that the Ts16 pallium is persistently reduced in volume because of a reduction in the number of cells and is also transiently delayed in radial growth between E13 and E18 (Haydar et al., 1996). After normalizing the volume indices at each embryonic day to the euploid cortical volume at E18, the predicted growth and the actual growth are in substantial agreement (Fig. 7).

\section{Effects of individual proliferative abnormalities}

Figure $6 B$ shows the predicted time course and extent of euploid and Ts16 neocortical histogenesis when all of the measured parameters $[Q, D, G F$, and number of cell cycles $(C C)]$ are incor- porated. To examine how changes in $Q, D, G F$, and $C C$ individually affect Ts16 neocortical growth, we repeated the calculations with and without changes in these parameters (Table 1). For euploid mouse neocortex, the calculations indicate that 144 postmitotic neurons are produced per founder cell by the end of neuronogenesis at E17 (Table 1, line 1), essentially identical to the 140 cells per founder reported previously (Takahashi et al., 1996a). Each of the next four lines of Table 1 shows the result of a calculation replacing one euploid parameter with the corresponding Ts16 parameter. When only the delay in $Q$ (from Fig. $5 B$ ) is incorporated into the euploid model (line 2), the resulting calculation predicts 262 neurons per founder cell, which would lead to a neocortex that is nearly twice normal size. Although there was a sixfold increase in apoptosis in the Ts16 PVE, incorporating the Ts16 level of death (Fig. 4) decreases output only by $\sim 3 \%$ (compare line 3 with line 2 ), suggesting that cell death does not significantly influence either Ts16 or euploid neocortical development. Including the reduced value of the Ts16 GF (Fig. 3) in the model reduces the predicted output by $\sim 18 \%$ (compare line 4 with line 3 ). Assuming only 10 rather than 11 CC during the neuronogenetic period further reduces the potential output by $28 \%$ (compare line 5 with line 4 ). Incorporating all of the Ts16 parameters except the founder cell reduction (Table 1, line 5) predicts a final neuron output per founder approximately equal to that in euploid neocortex. This analysis reveals that although changes in $D, G F$, and $C C$ tend to decrease the predicted number of Ts16 neocortical neurons, the delay in $Q$ causes such a large increase in the final number of neurons generated per founder cell that it essentially offsets the growth-limiting effects of the other parameters.

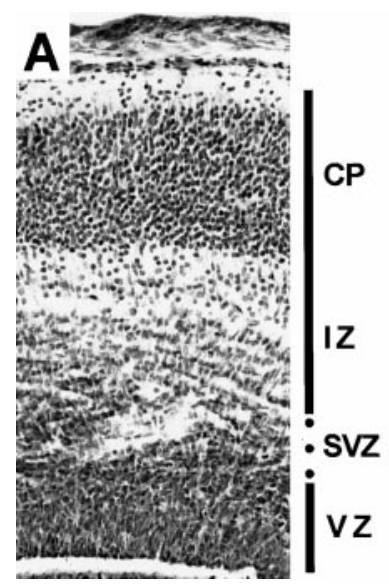

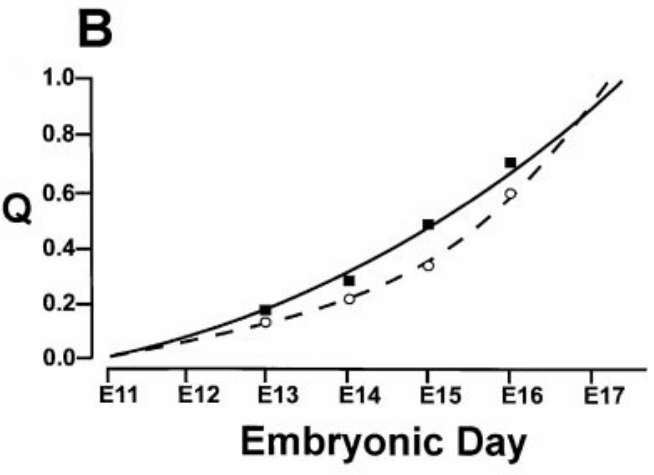

Figure 5. $Q$ is delayed during Ts16 neuronogenesis. $A, \mathrm{Nu}-$ clei within the cortical wall were counted and scored to be within the $V Z, I Z$, or $C P$. Nuclei within the $S V Z$ were omitted. $B, Q$ was measured by determining the fraction of postmitotic cells $(\mathrm{IZ}+\mathrm{CP})$ generated from the PVE between time points (Eq. 2), and $P$ was computed as $1-Q$. Values of $Q$ measured on E13, E14, E15, and E16 in euploid (squares; solid line) and Ts16 (circles; dashed line) cortices were fit with third-order regressions where $Q$ was forced through 0 at E11 and 1 at E17. The values of $Q$ for each cell cycle were then determined by interpolation [see Materials and Methods and Takahashi et al. (1996)]. 
Figure 6. Neuronogenetic model predictions for PVE growth and cumulative output for euploid (squares) and Ts16 (circles) neocortex. $A$, Using the experimentally determined values for founder cell number, $T_{\mathrm{C}}, G F, P$, and $D_{\mathrm{P}}$, Equation 3 was solved to give the PVE volume after each cell cycle. $B$, PVE volume (from Eq. 3), $T_{\mathrm{C}}, G F, Q$, and $D_{\mathrm{Q}}$ were incorporated into Equation 4 to predict the output of postmitotic cells from the PVE. The final cumulative output per founder from the Ts16 PVE is predicted to be about the same as in euploid neocortex.
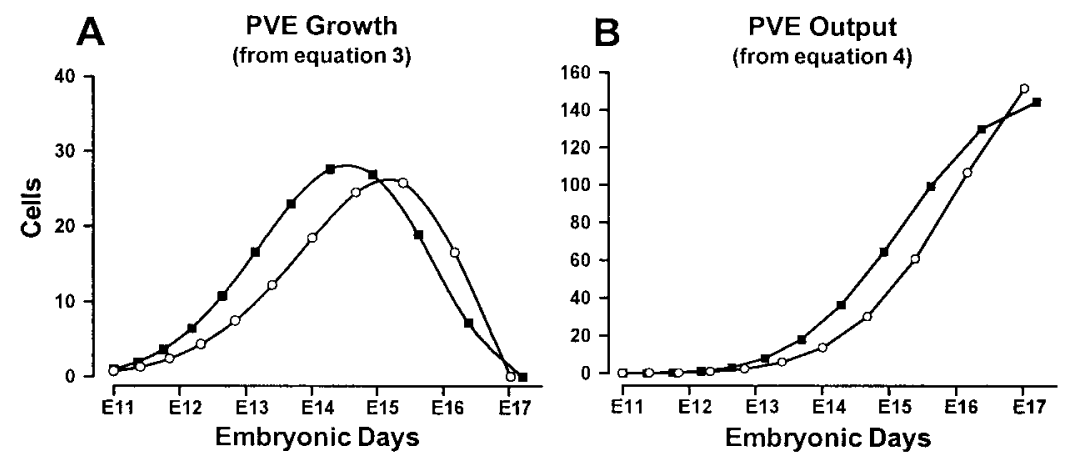

These results indicate that all of the Ts16 proliferative parameters act together during neuronogenesis to generate a neocortex that would be approximately the same size as control, euploid cortex if Ts16 and euploid cortices began with the same number of founder cells. However, the Ts16 neocortex begins with fewer founder cells and, accordingly, the Ts16 neocortex is smaller than euploid cortex despite the fact that each Ts16 founder cell generates a normal number of progeny during neuronogenesis (Fig. $6 B$, compare dotted line with solid Ts16 plot). When all Ts16 parameters (founder cells, $Q, D, G F, C C$ ) are combined in the model, the predictions of both the delayed growth and final size of Ts16 neocortex are in good agreement with the experimental results (Fig. 7). This strongly suggests that the changes in the measured parameters are sufficient to account for the known differences between the Ts16 and euploid phenotypes.

\section{DISCUSSION}

Our previous findings (Haydar et al., 1996) revealed that the embryonic development of the Ts16 neocortex is abnormal in at least two ways. First, the radial growth of the Ts16 neocortical wall is delayed during the middle of the neuronogenetic period,

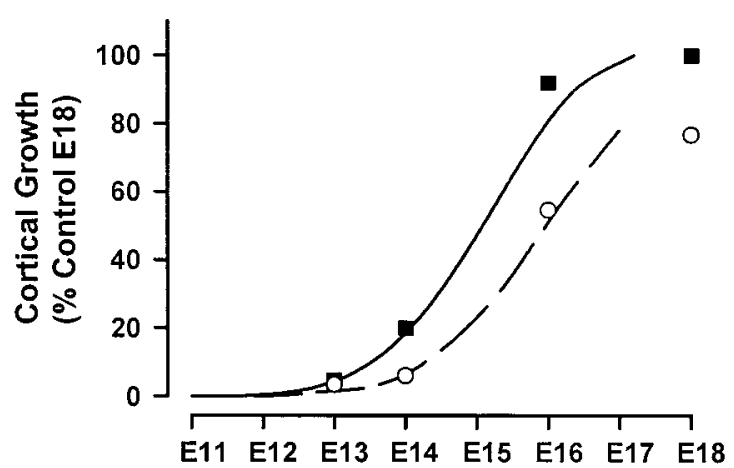

Figure 7. Comparison of observed neocortical growth with model predictions. The euploid telencephalic volume index at each embryonic day [computed from Haydar et al. (1996); see Materials and Methods] was normalized to the value at E18 (filled squares), which is expressed as $100 \%$ cortical growth. The euploid cumulative output (Fig. 5) was normalized by setting the maximal value $(C C=11$ at E18) to $100 \%$ (solid line). After scaling, the euploid model reasonably predicts the observed cortical growth throughout neuronogenesis. The Ts16 telencephalic volume indices from E11 to E18 were expressed as a percentage of euploid value at E18 (open circles). The Ts16 cumulative output model starting with a $26 \%$ founder cell reduction was then scaled by the same factor used to scale the euploid model, thereby also converting the Ts 16 model output to percentage normal growth (dashed line). The model predicts that the size of Ts16 neocortex (dashed line) is $22 \%$ less than that of euploid cortex toward the end of neuronogenesis, in good agreement with the observed Ts16 neocortical growth. but by the end of neuronogenesis the thickness of the Ts16 neocortical layers approaches that of the euploid neocortex. Second, the three-dimensional size of the Ts16 neocortex at E18, which reflects the total number of neurons produced, falls short of the euploid size by $\sim 25 \%$. These abnormalities could be explained by one or more of the following: (1) a smaller Ts16 progenitor (founder) cell population at the beginning of neuronogenesis, (2) altered kinetics of neuroblast proliferation, or (3) increased death of either progenitors or postmitotic neurons. An additional possibility, defective migration of postmitotic neurons out of the PVE, does not appear to contribute to the Ts16 phenotype because no obvious buildup of ectopic, postmitotic cells was observed in the Ts16 VZ (Haydar et al., 1996). Thus, in the present study, we examined the extent to which each of the first three potential causes contributes to the Ts16 phenotype.

\section{Delayed growth of the Ts16 neocortex is predicted from abnormalities in the PVE}

We documented several differences in properties of the Ts16 PVE, each of which would be expected to reduce the growth of the neocortex: a longer S-phase (Fig. 2), decreased GF (Fig. 3), as well as increased cell death in both the proliferative and postmitotic zones of the neocortical wall (Fig. 4) (Takahashi et al., 1997). However, more detailed analysis reveals that the consequences of the changes in these three parameters in the Ts16 neocortex are almost entirely offset at the end of neuronogenesis by the delayed increase in $Q$. As can be seen in Table 1 , if it were not for changes in $D, G F$, and $C C$, the Ts16 cortex would be almost twice the size of the euploid cortex. Despite the normal thickness of the Ts16 cortical wall at E18, the delayed increase in $Q$ appears to have profound consequences during the early and middle phases of Ts16 neuronogenesis (E12-E16). Because a lower $Q$ means that proliferating cells are more likely to return to the cell cycle than to exit (Fig. $5 B$ ), there is a delay in the generation of postmitotic Ts16 CP neurons up to about E16 (Fig. 6B). Importantly, this outcome, which is here deduced from the neuronogenetic model solved using measured euploid and Ts16 parameters, is virtually identical to the time course of radial thickness changes in the CP of Ts16 neocortex in vivo (Haydar et al., 1996). Thus, because of the changes in the proliferative parameters of the Ts16 PVE, the Ts16 neocortex eventually achieves a normal population of postmitotic neurons but at the expense of a delay in the generation of those neurons. Although our results provide no direct evidence for cause-and-effect relationships among proliferative parameters, it is possible that an alteration in one parameter in the Ts16 neocortex (e.g., the delayed increase in $Q$ ) is caused by genetically induced changes in other parameters (e.g., cell cycle duration, growth fraction, or cell death). 
Table 1. Contributions of individual parameters to neuronogenesis

\begin{tabular}{|c|c|c|c|c|c|c|}
\hline & \multicolumn{4}{|c|}{ Model parameter } & \multirow{2}{*}{$\begin{array}{l}\text { Predicted cumulative } \\
\text { output (cells/founder) }\end{array}$} & \multirow[b]{2}{*}{$\%$ Contro } \\
\hline & $Q$ & $D$ & $G F$ & $C C$ & & \\
\hline 1. & $\mathrm{E}$ & $\mathrm{E}$ & $\mathrm{E}$ & $\mathrm{E}$ & 144 & 100 \\
\hline 2. & $\mathrm{~T}$ & $\mathrm{E}$ & $\mathrm{E}$ & $\mathrm{E}$ & 262 & 182 \\
\hline 3. & $\mathrm{~T}$ & $\mathrm{~T}$ & $\mathrm{E}$ & $\mathrm{E}$ & 255 & 177 \\
\hline 4. & $\mathrm{~T}$ & $\mathrm{~T}$ & $\mathrm{~T}$ & $\mathrm{E}$ & 209 & 146 \\
\hline 5. & $\mathrm{~T}$ & $\mathrm{~T}$ & $\mathrm{~T}$ & $\mathrm{~T}$ & 151 & 105 \\
\hline 6. & $\mathrm{~T}$ & $\mathrm{~T}$ & $\mathrm{~T}$ & $\mathrm{~T}$ & $26 \%$ FC reduction & 78 \\
\hline
\end{tabular}

To use the neuronogenetic model to evaluate the relative contributions of individual Ts16 abnormalities to the output of the PVE at E17, calculations were done using various combinations of the euploid (E) or Ts16 (T) parameters, $Q$, cell death $(D)$, $G F$, and $C C$ (number of cell cycles). In the calculations in lines 1-5, the number of founder cells at the start of neuronogenesis was set to 1 . The resulting cumulative output (cells/founder) is shown for euploid cortex in line 1; lines $2-5$ show the results obtained when the calculation was repeated, sequentially replacing euploid values for $Q$ (line 2), $D$ (line 3 ), $G F$ (line 4), and $C C$ duration (line 5) with the corresponding Ts16 values. The output shown in line 5 was obtained using only the measured Ts16 parameters and reflects the expected output/founder cell of Ts16 neocortex (Fig. $6 B$ ). The value for the output in line 6 (box) is the value in line 5 adjusted for the measured reduction in founder cells in Ts 16 at the beginning of neuronogenesis (Fig. 1) and may be compared with the reduction in overall Ts16 cortical size determined at E17 (Fig. 7). The number of cell cycles in the Ts16 neuronogenetic period was reduced from $11(C C=\mathrm{E})$ to $10(C C=\mathrm{T})$ for the calculations in line 5. Values of $Q, D$, and $G F$ were taken from the data in Figures 5, 4, and $3 C$, respectively (see Results).

\section{Microencephaly with preservation of radial thickness}

Our results indicate that a reduction in the number of founder cells at the beginning of Ts16 neuronogenesis (Fig. 1) is sufficient to explain the smaller neocortex observed at the end of neuronogenesis (Fig. 7). Similarly, recent studies in monkey (Algan and Rakic, 1997) demonstrated that when neocortical progenitor proliferation is experimentally suppressed by irradiation in utero before the onset of neuronogenesis (reducing the founder cell population), the overall size of the resulting neocortex is reduced. Nevertheless, like the Ts16 neocortex at E18, the radial thickness was normal in irradiated monkeys. These results suggest that endogenous control mechanisms, operating locally within the cortical radial unit, ensure that normal cortical thickness, cell density, and cytoarchitecture are preserved at the expense of total cortical size. Both results may reflect the operation of similar adaptive mechanisms that control cortical expansion as predicted by the radial unit hypothesis (Rakic, 1988). Thus, abnormalities in Ts16 neuronogenesis may provide clues to the molecular mechanisms responsible for precise control of proliferation within a radial unit during normal cortical development.

Although our results indicate that the decreased size of the Ts16 neocortex at the end of neuronogenesis (E18) primarily results from a smaller founder cell population, not every instance of microencephaly can be attributed to a founder cell deficit. For example, although prenatal exposure to either toluene or ethanol also leads to reduced cortical size (Miller, 1986; Arnold et al., 1994) and ethanol exposure increases the length of the cell cycle of VZ cells (Miller and Nowakowski, 1991), important differences exist between these microencephalies and Ts16 with regard to the underlying mechanisms. In addition, embryopathies associated with both prenatal ethanol and toluene exposure involve migrational disorders that are not present in Ts16 (Miller, 1986; Arnold et al., 1994). Thus, the causes of the smaller Ts16 neocortex are distinct from those in other microencephalies.

\section{Potential consequences of a delay in radial expansion of the neocortex}

As discussed above, the delayed increase in $Q$ during Ts16 neuronogenesis contributes to the delayed radial growth of the neocortex during the middle of the neuronogenetic period (Haydar et al., 1996). This delay may have deleterious effects by upsetting the critical timing of the arrival of postmitotic neurons to the preplate and CP. Although the radial thickness of the Ts16 somatosensory cortex has "caught up" to that of the euploid neocortex by E18, the normal sequential pattern of arrival of pioneer (subplate and marginal zone) neurons, followed by arrival of CP neurons, may be disrupted by the delay in neuronogenesis in Ts16. Such a defect could alter the synaptic interactions between ingrowing afferents and neocortical neurons leading to permanent defects in connections within the neocortex and between the neocortex and subcortical regions (Molnar et al., 1998). Indeed, preliminary experiments suggest that, compared with euploid cortex, the extent of invasion of the CP by thalamocortical axons may be reduced in Ts16 at E18 (Haydar, 1997).

\section{Implications for Down syndrome}

The present results raise the possibility that one or more of the abnormalities in proliferation and survival observed in the Ts16 neocortex may be present in the neuroprogenitor population of the DS brain. This could contribute to the hypocellularity (Crome and Stern, 1972; Wisniewski et al., 1986; Schmidt-Sidor et al., 1990), abnormal lamination (Colon, 1972; Golden and Hyman, 1994), and decreased surface area (Weis, 1991; Wisniewski et al., 1993) of the DS neocortex. There are several indications that abnormalities in proliferation and survival are indeed present in DS. Rates of DNA synthesis, cellular doubling, and cerebral cortical levels of cyclin-dependent kinase are all decreased in DS (Schneider and Epstein, 1972; Bernert et al., 1996). The incidence of neuronal cell death may also be altered in the DS neocortex. Studies of primary neuronal cultures from both DS and mouse Ts16 fetal brains have demonstrated large increases in cell death (Bambrick et al., 1995; Busciglio and Yankner, 1995). In vivo evidence also suggests an increased rate of prenatal apoptosis in DS (Ross et al., 1984; Wisniewski and Dambska, 1992; Wisniewski and Kida, 1994). The genetic and phenotypic similarities between Ts16 and DS raise the possibility that the DS brain may also be adversely affected by a reduced founder cell population, altered neuroblast proliferation, and, possibly, abnormal cell death during prenatal development. Moreover, the analysis of Ts16 neocortical development described here may also help to shed light on the mechanisms regulating and coordinating proliferation and cell death in the normal human neocortex. 


\section{REFERENCES}

Algan O, Rakic P (1997) Radiation-induced, lamina-specific deletion of neurons in the primate visual cortex. J Comp Neurol 381:335-352.

Arnold GL, Kirby RS, Langendoerfer S, Wilkins-Haug L (1994) Toluene embryopathy: clinical delineation and developmental follow-up. Pediatrics 93:216-220.

Bambrick LL, Yarowsky PJ, Krueger BK (1995) Glutamate as a hippocampal neuron survival factor: an inherited defect in the trisomy 16 mouse. Proc Natl Acad Sci USA 92:9692-9696.

Bambrick LL, Yarowsky PJ, Krueger BK (1996) Glutamate-promoted survival in hippocampal neurons: a defect in mouse trisomy 16. In: Neurodegenerative diseases (Fiskum G, ed), pp 133-139. New York: Plenum.

Bernert G, Nemethova M, Herrera-Marschitz M, Cairns N, Lubec G (1996) Decreased cyclin dependent kinase in brain of patients with Down syndrome. Neurosci Lett 216:68-70.

Biggers WJ, Barnea ER, Sanyal MK (1987) Anomalous neural differentiation induced by 5 -bromo- 2 -deoxyuridine during organogenesis in the rat. Teratology 35:63-75.

Blaschke AJ, Staley K, Chun J (1996) Widespread programmed cell death in proliferative and postmitotic regions of the fetal cerebral cortex. Development 122:1165-1174.

Busciglio J, Yankner BA (1995) Apoptosis and increased generation of reactive oxygen species in Down's syndrome neurons in vitro. Nature 378:776-779.

Caviness Jr VS, Takahashi T, Nowakowski RS (1995) Numbers, time, and neocortical neuronogenesis: a general developmental and evolutionary model. Trends Neurosci 18:379-383.

Coggeshall RE, Prover CM, Kwait GC, Fitzgerald M (1993) Erythrocyte nuclei resemble dying neurons in embryonic dorsal root ganglia. Neurosci Lett 157:41-44.

Coggeshall RE, Lekan HA (1996) Methods for determining numbers of cells and synapses: a case for more uniform standards of review. J Comp Neurol 364:6-15.

Colon EJ (1972) The structure of the cerebral cortex in Down's syndrome. A quantitative analysis. Neuropaediatrie 3:362-376.

Crome L, Stern J (1972) Down syndrome. In: Pathology of mental retardation (Crome L, Stern J eds), pp 200-224. Edinburgh: Churchill Livingstone.

Ferrer I, Soriano E, del Rio JA, Alcantara S, Auladell C (1992) Cell death and removal in the cerebral cortex during development. Prog Neurobiol 39:1-43.

Gavrieli Y, Sherman Y, Ben-Sasson SA (1992) Identification of programmed cell death in situ via specific labeling of nuclear DNA fragmentation. J Cell Biol 119:493-501.

Golden JA, Hyman BT (1994) Development of the superior temporal neocortex is anomalous in trisomy 21. J Neuropathol Exp Neurol 53:513-520.

Gropp A, Kolbus U, Giers D (1975) Systematic approach to the study of trisomy in the mouse. II. Cytogenet Cell Genet 14:42-62.

Haydar TF (1997) Abnormal cortical histogenesis of the Trisomy 16 mouse. PhD thesis, University of Maryland School of Medicine.

Haydar TF, Blue ME, Molliver ME, Krueger BK, Yarowsky PJ (1996) Consequences of trisomy 16 for mouse brain development: corticogenesis in a model of Down syndrome. J Neurosci 16:6175-6182.

Haydar TF, Kuan C-Y, Flavell RA, Rakic P (1999) The role of cell death in regulating the size and shape of the mammalian forebrain. Cereb Cortex 9:621-626.

Hayes NL, Nowakowski RS (2000) Exploiting the dynamics of S-phase tracers in developing brain: interkinetic nuclear migration for cells entering versus leaving the S-phase. Dev Neurosci 22:44-55.

Holtzman DM, Epstein CJ (1992) The molecular genetics of Down syndrome. In: Molecular genetic medicine, Vol 2 (Friedmann T, ed), pp 105-120. San Diego: Academic.

Kornack DR, Rakic P (1998) Changes in cell-cycle kinetics during the development and evolution of the primate neocortex. Proc Natl Acad Sci USA 95:1242-1246.

Kriss JP, Revesz L (1962) The distribution and fate of bromodeoxyuridine and bromodeoxycytidine in the mouse and rat. Cancer Res 22:254-265.

Krueger BK, Burne JF, Raff MC (1995) Evidence for large-scale astrocyte death in the developing cerebellum. J Neurosci 15:3366-3374.

Kuida K, Zheng TS, Na S, Kuan C, Yang D, Karasuyama H, Rakic P, Flavell RA (1996) Decreased apoptosis in the brain and premature lethality in CPP32-deficient mice. Nature 384:368-372.

Kuida K, Haydar TF, Kuan C-Y, Gu Y, Taya C, Karasuyama H, Su MS-S, Rakic P, Flavell RA (1998) Reduced apoptosis and cytochrome c-mediated caspase activation in mice lacking caspase 9. Cell 94:325-337.
Miller MW (1986) Prenatal exposure to ethanol causes delayed and extended period of neurogenesis and results in microcephaly. Science 233:1308-1311.

Miller MW, Nowakowski RS (1991) Effect of prenatal exposure to ethanol on the cell cycle kinetics and growth proliferative zones of fetal rat cerebral cortex. Alcohol Clin Exp Res 15:229-232.

Molnar Z, Adams R, Blakemore C (1998) Mechanisms underlying the early establishment of thalamocortical connections in the rat. J Neurosci 18:5723-5745.

Nowakowski RS, Lewin SB, Miller MW (1989) Bromodeoxyuridine immunohistochemical determination of the lengths of the cell cycle and the DNA-synthetic phase for an anatomically defined population. J Neurocytol 1989 18:311-318.

Oppenheim RW (1991) Cell death during development of the nervous system. Annu Rev Neurosci 14:453-501.

Rakic P (1972) Mode of cell migration to the superficial layers of fetal monkey neocortex. J Comp Neurol 146:335-345.

Rakic P (1988) Specification of cerebral cortical areas. Science 241:170-176.

Rakic P (1995) A small step for the cell, a giant leap for mankind: a hypothesis of neocortical expansion during evolution. Trends Neurosci 18:383-388

Reeves RH, Gearhart JD, Littlefield JW (1986) Genetic basis for a mouse model of Down syndrome. Brain Res Bull 16:803-814.

Ross MH, Galaburda AM, Kemper TL (1984) Down's syndrome: is there a decreased population of neurons? Neurology 34:909-916.

Schmidt-Sidor B, Wisniewski KE, Shepard TH, Sersen EA (1990) Brain growth in Down syndrome subjects 15 to 22 weeks of gestational age and birth to 60 months. Clin Neuropathol 9:181-190.

Schneider EL, Epstein CJ (1972) Replication rate and lifespan of cultured fibroblasts in Down's syndrome. Proc Soc Exp Biol Med 141:1092-1094.

Spreafico R, Frassoni C, Arcelli P, Selvaggio M, De Biasi S (1995) In situ labeling of apoptotic cell death in the cerebral cortex and thalamus of rats during development. J Comp Neurol 363:281-295.

Sterio DC (1984) The unbiased estimation of number and sizes of arbitrary particles using the disector. J Microsc 134:127-136.

Takahashi T, Nowakowski RS, Caviness Jr VS (1992) BUdR as an S-phase marker for quantitative studies of cytokinetic behaviour in the murine cerebral ventricular zone. J Neurocytol 21:185-197.

Takahashi T, Nowakowski RS, Caviness Jr VS (1993) Cell cycle parameters and patterns of nuclear movement in the neocortical proliferative zone of the fetal mouse. J Neurosci 13:820-833.

Takahashi T, Nowakowski RS, Caviness Jr VS (1995a) The cell cycle of the pseudostratified ventricular epithelium of the embryonic murine cerebral wall. J Neurosci 15:6046-6057.

Takahashi T, Nowakowski RS, Caviness Jr VS (1995b) Early ontogeny of the secondary proliferative population of the embryonic murine cerebral wall. J Neurosci 15:6058-6068.

Takahashi T, Nowakowski RS, Caviness Jr VS (1996) The leaving or Q fraction of the murine cerebral proliferative epithelium: a general model of neocortical neuronogenesis. J Neurosci 16:6183-6196.

Takahashi T, Nowakowski RS, Caviness Jr VS (1997) The mathematics of neocortical neuronogenesis. Dev Neurosci 19:17-22.

Thomaidou D, Mione MC, Cavanagh JFR, Parnavelas JG (1997) Apoptosis and its relation to the cell cycle in the developing cerebral cortex. J Neurosci 17:1075-1085.

Weis S (1991) Morphometry and magnetic resonance imaging of the human brain in normal controls and Down's syndrome. Anat Rec 593:598.

Williams RW, Rakic P (1988) Three-dimensional counting: an accurate and direct method to estimate numbers of cells in sectioned material. $\mathrm{J}$ Comp Neurol 278:344-352.

Wisniewski KE, Dambska M (1992) Development and aging in Down's syndrome. In: Neurodevelopment, aging and cognition (Kostovic I, Knezevic S, Wisniewski HM, Spilich GJ, eds), pp 141-156. Boston: Birkhauser.

Wisniewski KE, Kida E (1994) Abnormal neuronogenesis and synaptogenesis in Down syndrome brain. Dev Brain Dysfunct 7:289-301.

Wisniewski KE, Laure-Kamionowska M, Connell F, Wen GY (1986) Neuronal density and synaptogenesis in the postnatal stage of brain maturation in Down syndrome. In: The neurobiology of Down syndrome (Epstein CJ, ed), pp 29-44. New York: Raven.

Wisniewski KE, Beaulieu I, Bobinski M, Lee MH, Castells S (1993) Microcephaly and neurological and neuropathological abnormalities in children with Down's syndrome. In: Growth hormone treatment in Down's syndrome (Castells S, Wisniewski KE, eds), pp 37-54. New York: Wiley. 